\title{
ANALISIS TAPIS INDUKTOR PADA STEP DOWN CHOPPER SATU FASA
}

\author{
AchmadMudawari \\ JurusanTeknikKonversiEnergi- PoliteknikNegeri Bandung \\ Mail: mudawari@yahoo.com
}

\begin{abstract}
Abstrak
Buck converter yang dilengkapi fiter LC dapat menghasilkan converter dengan riak yang rendah. Besarnya nilai tapis filter perlu dihitung dengan cermat terutama nilai inductor. Hal ini diperlukan agar converter bekerja pada konduksi kontinyu. Besarnya inductor dihitung berdasar energi rata-rata yang tersimpan pada filter.

Hasil simulasi menunjukan adanya hubungan antara nilai induktor dan daerah konduksi dari konverter apakah kontinyu atau diskontinyu.
\end{abstract}

Kata kunci:inductor filter LC filter, konduksi kontinyu, konduksi diskontinyu

\section{PENDAHULUAN}

DC chopper banyak digunakan sebagai power suply dan salah satu kriteria yang menyatakan kualitas power suply adalah riak yang kecil [1]. Ada beberapa macam topologi DC Chopper yaitu buck chopper, boost chopper, buck and boost chopper [2].

Pada tulisan ini dibahas buck konverter satu fasa dengan filter LC. Pembahasan dititik beratkan pada penentuan ukuran induktorfilter dengan menggunakan metoda rata-rata yang menyajikan batas kontinyu dan diskontinyuitas arus beban.

\section{TINJAUAN PUSTAKA}

\section{Topologi buck chopper}

Topologi buck chopper diperlihatkan pada gambar 1 [3][4][5].

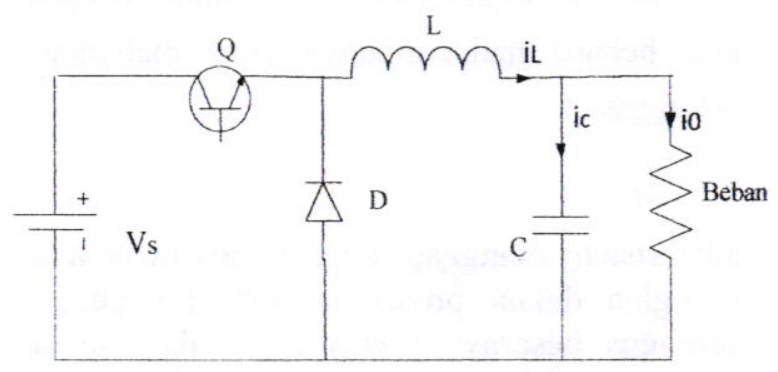

Gambar 1. Topologi buck chopper

\section{Prinsip kerja.}

Gambar 1 menggambarkan rangkaian buck chopper satu fasa dengan induktor (L) dan kapasitor (C) sebagai tapis keluaran.
Moda operasi Buck chopper ini dapat dibaga atas 2 moda yaitu pada saat transistor On dan pada saat transistor OFF. Apabila Transistor Q di-ON-kan (gambar 2.a) selama $t_{\text {on }}$ maka arus mengalir dari sumber melalui tapis induktor. Sedangkan pada saat OFF (gambar 2.b) energi yang tersimpan pada induktor akan dibuang kebeban melalui dioda $\mathrm{D}$.

Gambar 2 memperlihatkan moda operasi dari buck chopper yaitu pada saat transisitor ON dan pada saat transistor OFF.

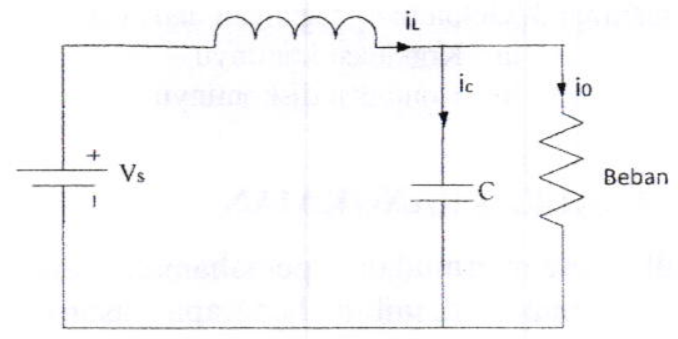

a)

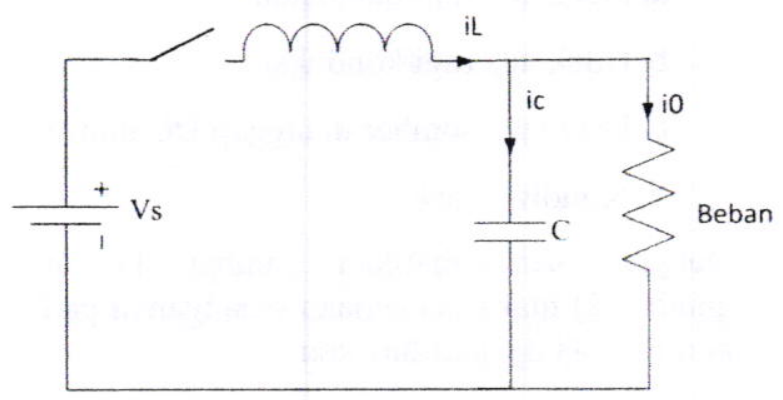

b)

Gambar 2. Rangkaian ekivalen

Sedangkan gambar 3 memperlihatkan bentuk gelombang tegangan dan arus keluaran. Gambar 3a) memperlihatkan bentuk 
gelombang arus keluaran kontinyu sedangkan gambar 3b) memperlihatkan bentuk gelombang arus yang diskontinyu.

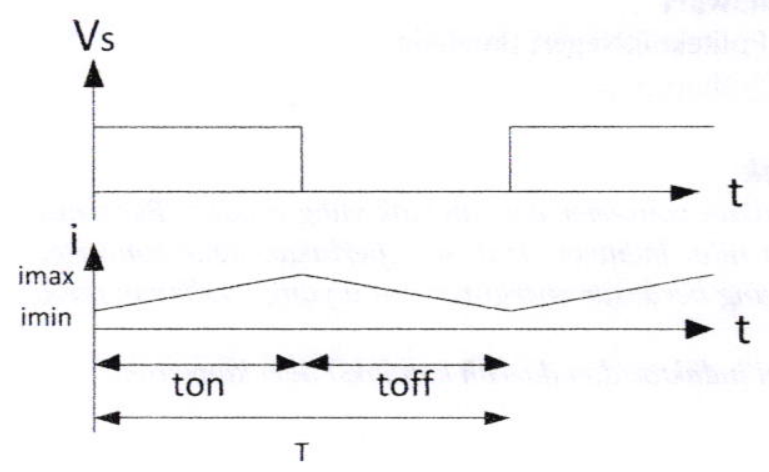

a)

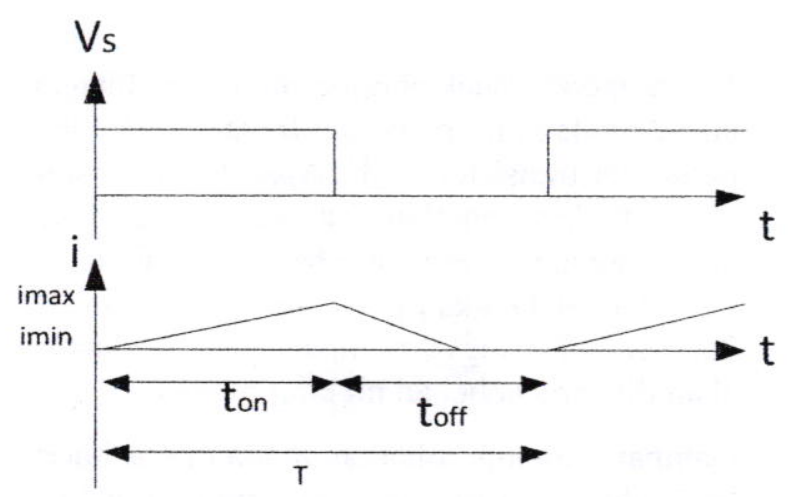

b)

Gambar 3. Gelombang tegangan dan arus
a. Konduksi kontinyu
b. Konduksi diskontinyu

\section{ANALISIS RANGKAIAN}

Untuk mempermudah pemahaman dan analisis maka diambil beberapa asumsi sebagai berikut :
a. Tidak ada rugi hambatan
b.Tidak ada rugi konduksi
c. Tegangan sumber dianggap DC murni
d. Kondisi tunak

Dengan memperhatikan gambar 1) dan gambar 2) maka persamaan teganganya pada kondisi $\mathrm{ON}$ dapat dilutiskan

$V_{s}=R i+L \frac{d i}{d t}+V_{0}$

Jika rugi-rugi hambatan di abaikan maka $L \frac{d i}{d t}=V_{s}-V_{0}$ $\frac{d i}{d t}=\frac{V_{s}-V_{0}}{L}$

$I_{\max }-I_{\min }=\frac{V_{s}-V_{0}}{L} t_{o n}$

Sedangkan pada kondisi OFF persamaan teganganya dapat dituliskan sebagai berikut :

$$
\begin{aligned}
& L \frac{d i}{d t}=-V_{0} \\
& \frac{d i}{d t}=-\frac{V_{0}}{L}
\end{aligned}
$$

$I_{\min }-I_{\max }=-\frac{V_{0}}{L} t_{\text {off }}$

Dari persamaan 3 dan 4 maka,

$$
\begin{aligned}
& \frac{V_{s}-V_{0}}{L} t_{\text {on }}=\frac{V_{0}}{L} \cdot t_{\text {off }} \\
& \left(V_{s}-V_{0}\right) \cdot t_{o n}=V_{0 .} t_{\text {off }} \\
& V_{s} t_{o n}=V_{0 .}\left(t_{o n}+t_{0 \text { off }}\right) \\
& V_{s} \cdot t_{o n}=V_{0 .}\left(t_{o n}+t_{0 f f}\right)
\end{aligned}
$$

$V_{s} t_{o n}=V_{0} T$

$\frac{V_{0}}{V_{s}}=\frac{t_{\text {on }}}{T}=D$

D adalah duty cycle

Dari Gambar 1 terlihat bahwa

$i_{c}=i_{L}-i_{0}$.

Jika nilai $i_{c}$ sangat kecil disbanding dengan arus beban $i_{0}$ maka nilainya dapat diabaikan sehingga

$i_{L}=i_{0}$

Jika sistem dianggap ideal berarti tidak ada kerugian dalam proses maupun komponen sehingga besarnya energi input akan sama dengan besarnya energi output. Besarnya energi yang terpakai selama proses dapat dihitung dari besarnya arus rata-rata dikali dengan besarnya tegangan selama satu periode sehingga, 


$$
\begin{aligned}
& \frac{1}{2}\left(i_{\max }+i_{\min }\right) \cdot V_{s} \cdot t_{o n}+\frac{1}{2}\left(I_{\min }+I_{\max }\right) V_{s} \cdot t_{o f f} \\
& \frac{1}{2}\left(i_{\max }+i_{\min }\right) \cdot D \cdot V_{s} \cdot T+\frac{1}{2}\left(I_{\min }+I_{\max }\right)(1-D) \cdot V_{s} \cdot T \\
& \frac{1}{2}\left(i_{\max }+i_{\min }\right) V_{s} \cdot . T \\
& \frac{1}{2}\left(i_{\max }+i_{\min }\right) \frac{V_{s}}{f}
\end{aligned}
$$

Daya adalah energi yang dipakai dalam satu satuan waktu, sehingga daya inputnya adalah

$$
P_{i n}=\frac{1}{2}\left(i_{\max }+i_{\min }\right) V_{s}
$$

Sedangkan besarnya daya output

$$
P_{\text {out }}=\frac{V_{0}^{2}}{R}
$$

Oleh karena system dianggap tidak ada kerugian maka besarnya daya input akan sama dengan besarnya daya output sehingga,

$$
P_{\text {in }}=P_{\text {out }}
$$

Sehingga,

$$
\begin{aligned}
& \frac{1}{2}\left(i_{\max }+i_{\min }\right) V_{s}=\frac{V_{0}^{2}}{R} \\
& \left(i_{\max }+i_{\min }\right)=\frac{2}{V_{s}} \cdot \frac{V_{0}^{2}}{R} \\
& \left(i_{\max }+i_{\min }\right)=\frac{2}{V_{s}} \cdot \frac{\left(D \cdot V_{s}\right)^{2}}{R} \\
& \left(i_{\max }+i_{\min }\right)=\frac{2}{R} \cdot D^{2} \cdot V_{s}
\end{aligned}
$$

Seperti diketahui bahwa

$$
\begin{aligned}
& \left(i_{\text {max }}-i_{\text {min }}\right)=\frac{V_{s}}{L} t_{\text {on }} \\
& \left(i_{\text {max }}-i_{\text {min }}\right)=\frac{V_{s}}{L} \cdot D \cdot T
\end{aligned}
$$

Dari persamaan 8 dan 9 diperoleh,

$$
2 . I_{\max }=\frac{2}{R} D^{2} . V_{s}+\frac{V_{s}}{L} \cdot D . . T
$$

$$
\begin{aligned}
& 2 \cdot I_{\max }=D \cdot V_{s}\left(\frac{2}{R} \cdot D+\frac{T}{L}\right) \\
& I_{\max }=D \cdot V_{s}\left(\frac{D}{R} \cdot+\frac{T}{2 L}\right)
\end{aligned}
$$

Jika persamaan 10) dimasukkan kepersamaan 9) maka diperoleh :

$$
\begin{aligned}
& i_{\min }=I_{\max }-\frac{V_{s}}{L} \cdot D \cdot T \\
& i_{\min }=D \cdot V_{s}\left(\frac{D}{R}+\frac{T}{2 L}\right)-\frac{V_{s}}{L} \cdot D \cdot T \\
& i_{\text {min }}=\frac{V_{s}}{R} \cdot D^{2}+D V_{s} T\left(\frac{1}{2 L}-\frac{1}{L}\right) \\
& i_{\text {min }}=\frac{V_{s}}{R} \cdot D^{2}-\frac{1}{2} \cdot \frac{V_{s}}{L} \cdot D \cdot T
\end{aligned}
$$

\section{Menentukan nilai $\mathbf{L}$ kritis}

Untuk menentukan batas nilai induktor kritis tercapai apabila besarnya arus minimum sama dengan nol atau konduksi akan diskontinyu apabila besarnya arus minimum mencapai harga nol maka.

$$
\begin{aligned}
& \frac{D^{2}}{R} \cdot V_{s}-\frac{1}{2} \cdot \frac{D V_{s} T}{L}=0 \\
& \frac{D^{2}}{R} \cdot V_{s}=\frac{1}{2} \cdot \frac{D V_{s} T}{L} \\
& \frac{D^{2}}{R} \cdot V_{s} \cdot L=\frac{1}{2} \cdot D V_{s} T \\
& L=\frac{1}{2} \cdot D V_{s} T \cdot \frac{R}{D^{2} V_{s}} \\
& L=\frac{R \cdot T}{2 D}
\end{aligned}
$$

Peramaan 12) merupakan nilai induktor kritis yang merupakan batas minimum nilai induktor yang mengakibatkan konduksi kontinyu atau diskontinyu.

\section{HASIL SIMULASI}

Untuk memperjelas sejauh mana pengaruh kontinyuitas arus beban dapat dilihat pada hasil simulasi berikut : 


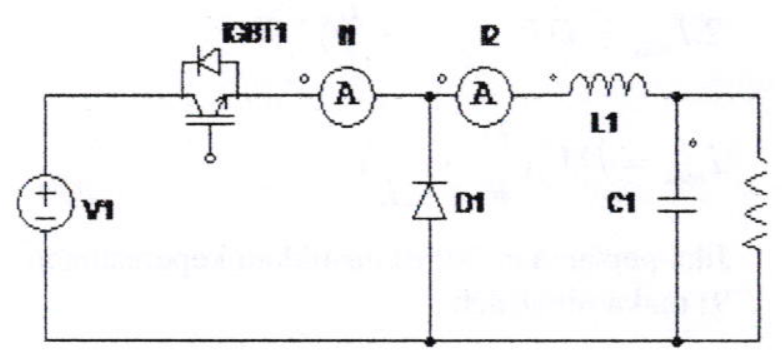

Gambar 4. Gambar rangkaian untuk simulasi

Parameter yang dipakai simulasi menghasilkan gambar 5 - 7 adalah sebagai berikut :

$\mathrm{V} 1=20 \mathrm{~V}$

$\mathrm{Ll}=0.001 \mathrm{H}$

$\mathrm{Cl}=0.001 \mathrm{~F}$

Frekuensi switching $=1000 \mathrm{~Hz}$

Duty cycle 0.5

$\mathrm{R}=2.9 \mathrm{Ohm}$

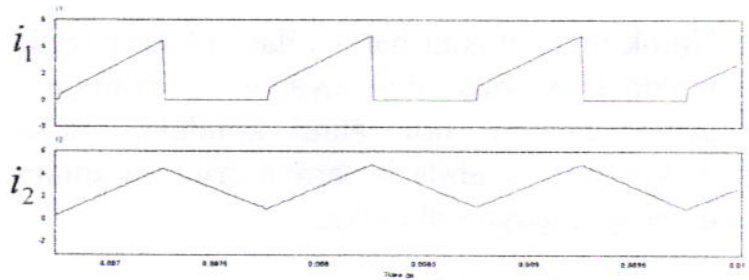

Gambar 5. Hasil simulasi pada nilai beban $2,9 \Omega$

$\mathrm{R}=5 \mathrm{Ohm}$

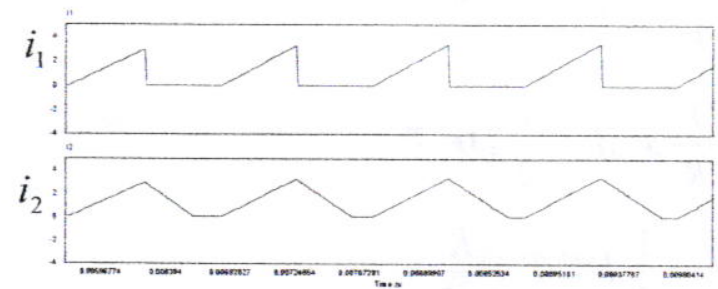

Gambar 6. Hasil simulasi pada nilai beban $5 \Omega$

$\mathrm{R}=10 \mathrm{Ohm}$

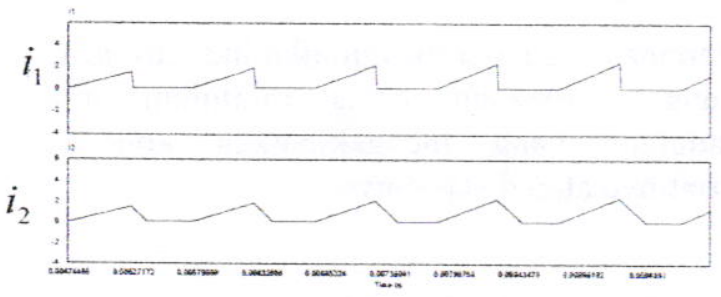

Gambar 7. Hasil simulasi pada nilai beban $10 \Omega$

Parameter yang dipakai simulasi menghasilkan gambar 8 - 10 adalah sebagai berikut :
$\mathrm{V} 1=20 \mathrm{~V}$

$\mathrm{L} 1=0.001 \mathrm{H}$

$\mathrm{Cl}=0.001 \mathrm{~F}$

Frekuensi switching $=1000 \mathrm{~Hz}$

$\mathrm{R}=10 \mathrm{Ohm}$

Duty cycle 0.25

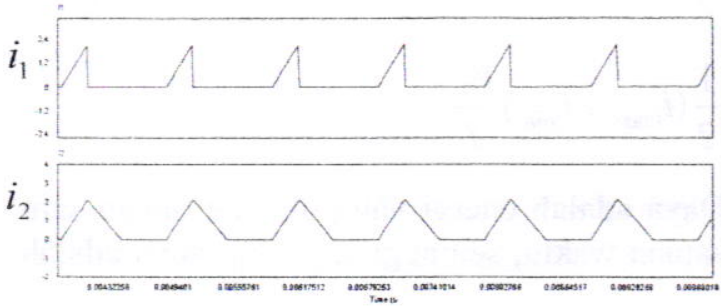

Gambar 8. Hasil simulasi pada Duty cycle 0.25

Duty cycle 0.5

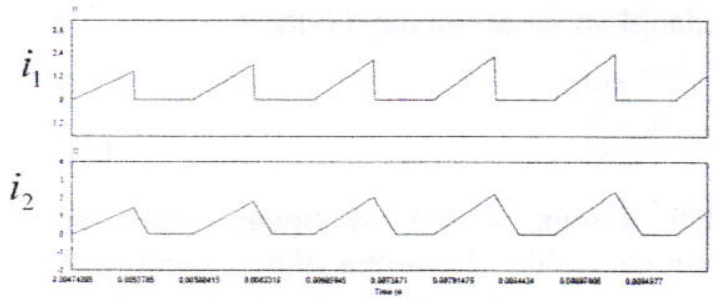

Gambar 9. Hasil simulasi pada Duty cycle 0.5

Duty cycle 0.75

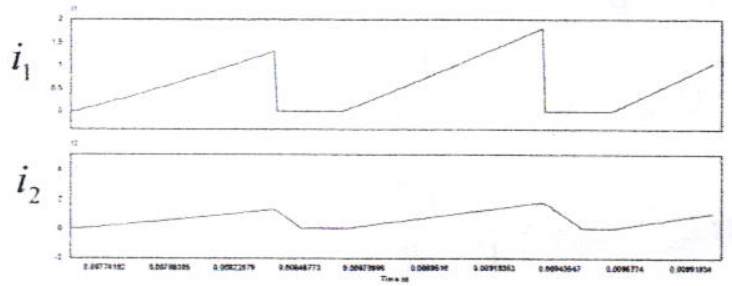

Gambar 10. Hasil simulasi pada Duty cycle 0.75

Gambar 5 - 7 memperlihatkan hasil simulasi buck chopper untuk duty cycle 0,5 dengan variasi beban resistor berbeda. Dari gambar tersebut terlihat bahwa untuk duty cycle yang sama besarnya beban resistor berpengaruh terhadap kontinyuitas arus benan.

Sedangkan dari gambar $8-10$ terlihat bahwa untuk beban resistor yang samadengan duty cycle yang dibuat variasi ternyata arus beban tetap diskontinyu. Dari uraian tersebut terlihat bahwa untuk induktansi yang sama besarnya beban resistor akan mempengaruhi kontinyu dan tidaknya arus beban. 


\section{KESIMPULAN}

Dari hasil analisis dan simulasi dapat disimpulkan bahwa:

1. Untuk tegangan, inductor dan duty cycle yang sama, kontinyu dan tidaknya arus beban dipengaruhi oleh besar beban resistor yang tersambung.

2. Untuk tegangan, inductor dan resistor yang sama, kontinyu dan tidaknya arus beban tidak dipengaruhi oleh duty cycle.

\section{DAFTAR PUSTAKA}

[1] Hermawan Ilmanda, Mochammad Facta, Karnoto, "Pembuatan Catu Daya Arus Dc Menggunakan Topologi Inverter Jembatan Penuh Dan Penyearah", TRANSMISI Vol 16, No 1 (2014)
[2] Marco Arief Juarsah, Mochammad Facta, Agung Nugroho, "Perancangan Dc Chopper Tipe Buck-Boost Converter Penguatan Umpan Balik Ic Tl 494", TRANSIENT, VOL.4, NO. 3, SEPTEMBER 2015, ISSN: 2302-9927, 598

[3] Abraham I. Pressman, "Switching Power supply Design", McGraw Hill Internatinal editions 1991

[4] Caballero and Barbi, "A New FlybackCurrent-Fed Push-Pull DC-DC Converter", IEEE Trans. on Power Electronics, vol.14, no 6, Nov. 1999

[5] MD Singh, "Power Electronis", Tata McGraw Hill Publishing Company Limited New Delhi 2007 